\title{
Exploration and Practice on the Three-dimensional Training Mode for Special Children's Art Rehabilitation Talents
}

\author{
Qiuzhu Liu \\ School of Education Science \\ Leshan Normal University \\ Leshan, Sichuan, China 614000
}

\author{
Xingmei Dong \\ School of Education Science \\ Leshan Normal University \\ Leshan, Sichuan, China 614000
}

\begin{abstract}
The three-dimensional training mode, including course teaching, rehabilitation practice and network teaching, is probed in this paper for special children's art rehabilitation, on the basis of teaching reform. This mode mainly solves problems, such as insufficient practical ability of art rehabilitation, limited learning scope, the short learning period, shortage of learning resources, and neglecting students' dominant role and teachers' professional development. The initiative of this mode lies in the balance between theory and practice, foundation and improvement, and school education and lifelong learning; the combination of students' development and teachers' promotion, and social services. Fair achievements have been acquired through the training mode in cultivating teachers for special children's art rehabilitation and the real art rehabilitation of special children and their parents.
\end{abstract} mode

Keywords-art rehabilitation; the three-dimensional training

\section{INTRODUCTION}

The 12th Five-Year Development Program of China Undertaking for Disabled Persons (2011-2015) clearly pointed out to "implement the rescue rehabilitation project free for $0 \sim 6$ year-old disabled children". It is badly in need of a large number of talents who have professional skills to involve in special children's rehabilitation and special education. In 2014, Special Education Promotion Plan (2014-2016) clearly put forward "to accelerate to the development of special education and to vigorously improve the special education level". It also proposed some countermeasures to solve the shortage of special education teachers and rehabilitation technicians and promote the professional level of relevant personnel. It is to "enhance the construction of special education teaching staff and their professional level".

Art rehabilitation is one of the important rehabilitation means for curing special children. It uses the creation of art as a medium to promote special children's physical and mental development. At present, we are still in a new developing stage. The problem is that we lack professionals. So, it is crucial to construct an art rehabilitation talent training mode with solid

This paper is about the practice and exploration results in network teaching of special children's art rehabilitation, a teaching reform project of Leshan Normal College, in 2015. The project number: JG2015-YB40. art rehabilitation knowledge and professional skills in the cultivation of special children's art rehabilitation teachers.

\section{THE CONNOTATION OF THE THREE-DiMENSIONAL TRAINING MODE}

The three-dimensional training mode for special children's art rehabilitation talents is based on the traditional teaching. Relying on the teaching practice platform of our special children's rehabilitation center, combined with the school-level teaching reform of "network teaching practice and exploration of special children's art rehabilitation, the authors construct such an applied special education rehabilitation talent training mode focusing on course teaching, education rehabilitation practice and network teaching. Among them, the teaching of art rehabilitation course group helps students grasp theoretical system of special children's art rehabilitation. Students could establish a reasonable art rehabilitation view. The education and rehabilitation practice is designed to cultivate and improve students' art rehabilitation practice operating skills and level. Network study could not only expand students' study time span and promote relationships between students and teachers and the exchange and cooperation between parents and school. The three aspects complement each other and jointly promote students' special children's art rehabilitation skills and ability.

From the beginning of September 2013, we have gradually established and improved the three-dimensional training mode for special children's art rehabilitation talents. Over the past three years, with the support of this mode, we have achieved initial results in the cultivation of undergraduate talents, the improvement of the professional ability of teachers, the education and rehabilitation on special children, and social services.

\section{The Main Teaching Problems that the ThreE- DIMENSIONAL TRAINING MODE CAN SOLVE}

At present, special schools and rehabilitation institutions are in urgent need of special children's art rehabilitation teachers. But it is difficult to cultivate high-quality art rehabilitation talents only by traditional classroom teaching. The three-dimensional talent training mode could solve the following teaching problems. 


\section{A. The Disconnection between Theory and Practice and the} Lack of Practical Ability on Education and Rehabilitation

The special children's art rehabilitation curriculum is reasonable in arrangement and the teaching content is beneficial for students to grasp an overall and systematic theoretical knowledge. Its exploration on psychological level is profound. But it is difficult to explore special children's psychological mechanism individually and its education rehabilitation practice from the view of art. Thus, students could grasp the systematic art rehabilitation theory but lack the practical application ability on art rehabilitation. Lacking direct experience and theoretical support, students are difficult to accept the knowledge and theory of interdisciplinary subjects, so that the course teaching becomes a mere formality.

\section{B. The Lack of Learning Width and Depth and the Short Learning Period}

The Special Education and Rehabilitation Talent Training Plan for 2015-enrolled Students has set a lot of programs. The course hours of each program are shortened. The educational rehabilitation and art rehabilitation of special education separately have 8 and 6 credits in total. Art rehabilitation contains art therapy, drama therapy, music therapy, dance therapy and many other categories. It requires students to master psychology and have basic quality of artistic fields. Students should have effective art rehabilitation skills and the knowledge about special children's physical and mental characteristics. Students will be unable to grasp professional knowledge and skills in width and depth only by classroom teaching. In addition, most of students study only by attending class, and have no motives to extend their learning period. But with the three-dimensional training mode, students could learn after class and participate in educational practice at special children's center at least for three semesters. Relying on network resources, students could learn relevant knowledge of art rehabilitation even after they graduate or take a job. It effectively extends students' learning time span and study width.

\section{The Lack of Learning Resources}

At present, there are a lot of works about art therapy and music therapy. There are only a few works on drama therapy let alone children's drama education books. We rarely see books of practical operation, especially on children's art rehabilitation. Therefore, our team have been constructing and perfecting our network teaching resources, including WeChat platform of special children's art therapy and relevant section under our school's home page, as we promote it among teachers, specialists, college students and special children and their parents. What's more, we have compiled Theory and Practice on Special Children's Art Rehabilitation. Now we are compiling Practical Training Guideline about Special Children's Art Rehabilitation. So, we sort and integrate all aspects of resources and provide them to students.

\section{Neglecting Students' Dominant Role and Some Students Lacking Initiative in Learning}

At present, our teaching form is still in class-based teaching system and classroom teaching. Our teachers are active to make innovation and reform and fully respect students' dominant role from idea. But if we see from teaching design, assessment method and speech right in class, teachers are still in a dominant role. The three-dimensional mode could change teaching scene and teaching role. Teachers transfer from leader into director and network resource managers. Students transfer from educatee into teaching assistants, teachers and users and maintainers of network resources. Students' dominant role are fully respected and realized, and their learning initiatives are inspired.

\section{E. The Insufficient Support for Teachers' Professional Development}

Special children's art rehabilitation curriculum requires teachers to have high artistic accomplishment and solid psychology foundation. Teachers should master comprehensive knowledge and skills of special children's educational rehabilitation and professional quality. The number of teachers who can give art rehabilitation is rare. It is important to thoroughly teach a multi-disciplined comprehensive course, which is essential to cultivate students' art rehabilitation practice ability. It gives a great challenge to teachers' teaching. Thus, a study platform should be established for joint study, discussion and interaction of teachers, students, special children and their parents and specialists in art rehabilitation field. The three-dimensional training mode not only could facilitate students to study art rehabilitation knowledge and teachers to develop their professional, but also greatly support the teaching reform and scientific research. Over the past three years, our teachers have been greatly improved in the teaching reform, student guidance and scientific research.

\section{THE SPECIFIC OPERATING METHODS OF THE THREE- DIMENSIONAL TRAINING MODE}

The three-dimensional training mode for special children's art rehabilitation talents has integrated the advantages of three fields, curriculum teaching, special children's art rehabilitation practice and network teaching, so it can solve about problems effectively. Specific methods of operation are as follows:

\section{A. The Course Teaching}

Course teaching is the foundation of the three-dimensional training mode. Starting from 2015-enrolled students, our school began to arrange more reasonable and rich art rehabilitation courses. As for students of education rehabilitation specialty, we set up introduction to special children's art therapy ( 2 credits for the third semester), special children's art therapy ( 2 credits for the fourth semester), special children's drama therapy ( 2 credits for the fifth semester), and special children's music therapy ( 2 credits for the sixth semester). As for students of special education specialty, we set up art rehabilitation foundation ( 3 credits for the fifth semester) and art rehabilitation practice ( 3 credits for the sixth semester). Reasonable course arrangement and class order ensure that students could grasp basic theoretical knowledge of art rehabilitation and develop art rehabilitation ability.

On teaching ideas, special children's art rehabilitation course focuses both on theoretical study and educational 
rehabilitation practice. The teaching gives a lot of professional theories and allows students to practice and reflect. It combined the unique developing need of special children and difficulties to carry on the activity of art therapy. Therefore, it stresses basic theories of psychology and art therapy and the theoretical study of the three major fields, art therapy, drama therapy and music therapy, and attaches great importance to special children's art rehabilitation practice.

Each course has both classroom teaching hours and practical training hours. Compared with rich theoretical content and practical training of art rehabilitation, the teaching hours are relatively few. To expand students' study depth and width and arouse their interests in learning, we use the public WeChat of "Special Children's Art Rehabilitation" and the section of "art rehabilitation" on Sichuan Special Education Network, in combination with the reform of task of "Network Teaching of Special Children's Art Treatment Course". It not only provides rich study resources for students but also expands their learning width and extends their learning period. The teaching in practical training is led by teachers and given by students. Students participate in experience and reflection on art rehabilitation activity. The course assessment gives consideration to both daily study and final exam. We use a compressive assessment method in four courses, Special Children's Art Therapy, Special Children's Drama Therapy, Special Children's Music Therapy and Art Rehabilitation Practice.

\section{B. The Practical Teaching of Art Group in the Special Children's Education and Rehabilitation Center}

Special Children's Education and Rehabilitation Center is an organization to give special children education and rehabilitation. It is affiliated to College of Special Education. It is not only committed to providing education and rehabilitation for special children and their parents but also is an educational practice base for our students. At same time, it is also our teachers' scientific research base. It plays an important supporting role for the development of teachers and students in our college and the development of special children and their families.

To guarantee the smooth operation of the Special Children's Education and Rehabilitation Center, effectively carry out education and rehabilitation on special children and promote students' practical ability, since the foundation date of the center, we have established the art group and gradually perfect the operation of its group scheme. The work program clearly sets out the objectives, core concepts, work flow and the arrangement of each semester.

The objective of the art group is to conduct psychological and emotional adjustment through expressive art, especially in the form of art and drama. The specific objectives include: helping individuals understand their emotion and adjust bad mood by means of art, cultivating their aesthetic view in art activities, helping individuals establish positive self concept by means of art and develop a good interpersonal relationship, and helping individuals freely associate with the world and establish a harmony relations by means of art.
The work flow of art group: take over cases - evaluate develop a semester plan - develop design cards of teaching activities - submit for amendment, approval and execution carry out teaching activities and record teaching observations make teaching reflection - make final assessment - make a semester summary.

The learning stage of practical training students in the art group includes: carry out two-way selection and voluntarily join in the group - study theories of this field under guidance of teachers - act as assistant teachers and guide assistant teachers - act as leading teacher and guide assistant teacher finish educational practice and continue to participate in the network training. Self study and group discussion are very important activities running through the whole education and rehabilitation activities. It is an important mechanism to guarantee students' learning.

In order to ensure the quality of education and rehabilitation, the students and teachers in the group are required to establish a humane education and rehabilitation concept, carry out all rehabilitation and education activities positively and initiatively, give education and rehabilitation strictly according to work flow and make reflection and summary carefully.

Over the past three years, the majority of special children were willing to attend class in the art rehabilitation group and they actively participate in class activities. Most parents have felt and accepted changes of their children's emotional expression and management, self cognition, interpersonal aspects. College students participating in the practice also said they were inspired and have motive to study and practice art rehabilitation in the future when they saw changes of these special children.

\section{The Construction and Use of Network Learning Resources}

Our team set up two network teaching platforms: the art rehabilitation section in Sichuan Special Education Network and the public WeChat of special children's art rehabilitation.

We should do a good job in the construction of database in order to play the role of network teaching through website and the public WeChat. We plans to set up the following sections to expand student's' study resources: theories (including teaching outline, plan, courseware and lecture supplement on art rehabilitation), cases (to show and share designs of teachers and students in Special Children's Center of Art Rehabilitation and excellent art rehabilitation cases), reading (to recommend book list and share reading experience), footmark (to report professional activities and social service of art rehabilitation teachers and students, birthday (to share students' experience), research (to share teachers and students' research experience and fruits. Among them, online workshop is its characteristic, which is carried out with the planning and leading of art rehabilitation teachers, and relying on the art rehabilitation section in Sichuan Special Education Network and the public Wechat of special children's art rehabilitation. Teachers launch detail art rehabilitation activity plan and students learn it individually or collectively, and make art creation. Then report and show students' works and activity experience. Last, instructors give feedback. The online workshop could expand 
students' study width of art rehabilitation and extend their learning and practice time span. Lower grade students and graduates also can participate.

With Sichuan Special Children Education Network and the public WeChat of special children's art rehabilitation, it is more convenient for teachers, students and parents to communicate with each other. They could exchange and discuss regularly or irregularly, individually or collectively. We accept submission, open comments and receive message reply.

\section{THE INNOVATIONS OF THE THREE-DIMENSIONAL TRAINING MODE}

The three-dimensional training mode for special children's art rehabilitation talents takes course learning as basis in the exploration and practice, education and rehabilitation as core, and serving special children and families as social value carrier. It, based on theoretical study and practice, promotes scientific innovation of teachers and students. The four aspects interplay each other and improve together, which benefits our college students, teachers, special children and their families.

\section{A. The Three-Dimensional Talent Training Mode Paying Equal Attention to Theory and Practice, Foundation and Promotion, School Education and Lifelong Learning}

The three-dimensional talent training mode, integrating course learning, education and rehabilitation practice and network teaching, combines theory and practice organically, deepens course learning through education and rehabilitation practice, and improves practical ability by systematical course learning. It integrates school education and lifelong study and combines course learning and extracurricular practice from study depth, width and lasting time.

\section{B. The Organic Unity of Students' Development, Teachers' Promotion and Social Service}

The three-dimensional training mode for special children's art rehabilitation talents not only promotes the professional development of our college students but also improve teachers' professional level. It is an effective mode to study and solve problems in teaching and research. After grasping basic knowledge and skills, teachers and students can serve special children, their families and communities directly. Thus, take the responsibility of serving the society.

On the basis of the practice of course teaching and art education and rehabilitation, the teachers and students in the art group combined discovered problems in education and rehabilitation, and positively make reflection and research. Over three years, we have achieved prominent achievements. The instructors in the group have held three department-level research subjects, participated in eight scientific projects, one school-level teaching reform subject and one school-level textbook project. 2012-enrolled special education students in the art group completed their thesis in high quality. Among them, Research on Case of Using Drawing Art Therapy to Intervening Retarded Children was named as excellent undergraduate thesis in our college.
The art group has carried out work for three years. We have provided service for 18 special children. We have given more than 600 class hours, including one-to-one art course, collective-teaching art course, collective-teaching drama course and collective-teaching music course. The effect of our education and rehabilitation has been widely recognized by parents. At the same time, we strengthen the cooperation between parents and school through face-to-face communication, parents' meeting, parents' lectures, network and other ways. It has given a strong support to the families of special children. In addition, the teachers and students of this group positively serve local special children in Leshan and give them education and rehabilitation service in the form of public lecture and education consulting.

\section{THE ACHIEVEMENTS, PROMOTION AND APPLICATION}

\section{A. The Promotion among Our College Students}

From September 2013 to this day, more than 40 education rehabilitation students enrolled in 2012, 2013, 2014 and 2015, have carried out education and rehabilitation practice for a period of 2 4 semesters. By education and rehabilitation practice and study, the students in this group have grasped solid special children's art rehabilitation theory and operating skills. They could undertake the teaching of special children's art rehabilitation course independently. Students enrolled in 2012 have graduated and they have been employed in municipal and county-level special schools and got recognition of their units.

\section{B. The Promotion among Special Children and Their \\ Families}

We have provided art rehabilitation service for 18 special children one after another. They have autism, mental retardation, hyperactivity and cerebral palsy, ranging in age from 7 to 18. They received art rehabilitation at least for three semesters or at most for five semesters. The art group opened one-to-one art course, collective-teaching art course, collectiveteaching drama course, collective-teaching music course. We have given four types of courses and more than 600 class hours for special children in total over the past three years. By faceto-face exchange, QQ Group, WeChat, we communicated and exchanged with parents and held parents' meeting and opened lectures for parents regularly in each semester. And we invited parents to share their experience. With good communication between family and school, we jointly are devoted to special children's rehabilitation and development.

\section{The Promotion in Teacher Training of Special Schools}

In a number of national and provincial teacher training in special schools undertaken by my college, teachers and students in the art group have acted as teaching experts, assistant teacher and volunteers. We finished the training tasks with high-quality lectures and vivid workshop. For example, Liu Qiuzhu acted as class teaching teacher of art rehabilitation teacher training class of special education schools in Tianfu Project in October 2013, and she gave the lecture of Children's Drawing Development Stage. In the demonstrative teacher training program Upgrade of Society-adaptation Education and Core Teachers' Teaching Skills in October 2015, she gave the 
lecture of Art Rehabilitation Activity Design and Implementation in Society-adaptation Schools. Dong Xingmei acted as class teaching teacher of art therapy teacher training class of special education schools in Tianfu Project and she gave the lecture of Psychological Foundation in Art Rehabilitation in October 2014. She also gave the lecture of Art Psychotherapy Mechanism and Drama Therapy in the demonstrative teacher training program Upgrade of Societyadaptation Education and Core Teachers' Teaching Skills in October 2015, and she led OSP Workshop.

\section{The Promotion in the Art Rehabilitation of Special Schools}

2012-enrolled students in the art group have graduated and they have taken up jobs. They bring their loved art rehabilitation to their jobs. Some of them act as teachers in music rehabilitation group in Leshan Special School and some as teachers in art rehabilitation group in Mianyang Youxian Special Education School. Teachers in the art group actively provide professional consulting and guidance to some other special education and rehabilitation institutions in Leshan. Meanwhile, we promote special children's art rehabilitation in provincial and national teacher training. Many teachers having participated in the art rehabilitation teacher training undertaken by our college said that they were benefiting from it. Many of them have combined art therapy with their discipline and made beneficial practice and exploration in later study.

\section{CONCLUSION}

For three years, we have achieved some results in the implementation of the three-dimensional training mode. Long as the way is we will keep on searching above and below. First, we have been committing to the construction of special children's art rehabilitation course group and speeding up the writing of professional textbooks and publishing them. Second, we will further integrate the education rehabilitation and course teaching for students practicing in Special Children's Education and Rehabilitation Center and provide fair study and practice opportunities for each student. They will be written into training program as an important link in "the training of teaching practice skills", so as to guarantee the training of students' practical skills in system. Last, we will further strengthen the construction and maintenance of network resources to make full use of it in study and sharing.

\section{REFERENCES}

[1] Deng Meng \& Zhao Meiju. Thinking on Reform of Special Education Teacher Training Mode in China's Higher Normal Schools under the Background of the Integration Education. Journal of Education, 2013 (6): 75-80.

[2] Fang Yi et al. Construction and Practice of Special Course Group of Art Resources in Normal Schools of Special Education. Chinese Vocational and Technical Education, 2015 (17): 87-91.

[3] Zhao Yuting. Problems in Chinese Drawing Therapy and Countermeasures. Journal of Heilongjiang College of Education, 2012 (11): 112-114.

[4] Zhou Hong. Art Therapy and its Application in Special Children Education. Chinese Journal of Special Education, 2007 (5): 68-73.
[5] Hao Zhenjun, Cao Yanying. A Preliminary Study of Art Therapy for Children with Intellectual Disabilities in Junior Grade. Chinese Journal of Special Education, 2004 (5): 27-30.

[6] Zhang Jinhua. Art Rehabilitation Education in Colleges and Universities. Popular Literature and Art, 2014 (20): 230-231.

[7] Zang Xiaoli, Li Yang \& Cui Leyou. Construction and Implementation of Art Psychotherapy Course Group of Applied Psychology in Private Colleges and Universities. Technological Equipment in Chinese Education, 2016 (10): 86-87.

[8] Liu Yang. Research and Construction of Modern Teaching System of Art Therapy. Grand View of Art, 2013 (1): 152-153. 